Report No. BMI-1290

UC-80 - Reactors - General

(TID-4500, 13th Ed., Rev.)

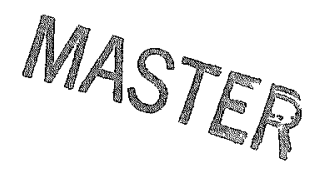

Contract No. W-7405-eng-92

\title{
AN IN-PILE GAS-COOLED LOOP INSTALLED \\ AT THE BATTELLE RESEARCH REACTOR
}

by

George T. Bodnar

Wallace J. Stevens

Gerald A. Francis

Sherwood L. Fawcett

Albert M. Rockwood

September 16, 1958

BATTELLE MEMORIAL INSTITUTE

$505 \mathrm{King}$ Avenue

Columbus 1, Ohio 


\section{DISCLAIMER}

This report was prepared as an account of work sponsored by an agency of the United States Government. Neither the United States Government nor any agency Thereof, nor any of their employees, makes any warranty, express or implied, or assumes any legal liability or responsibility for the accuracy, completeness, or usefulness of any information, apparatus, product, or process disclosed, or represents that its use would not infringe privately owned rights. Reference herein to any specific commercial product, process, or service by trade name, trademark, manufacturer, or otherwise does not necessarily constitute or imply its endorsement, recommendation, or favoring by the United States Government or any agency thereof. The views and opinions of authors expressed herein do not necessarily state or reflect those of the United States Government or any agency thereof. 


\section{DISCLAIMER}

Portions of this document may be illegible in electronic image products. Images are produced from the best available original document. 
ABSTRACT

INTRODUCTION

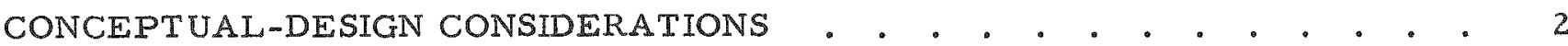

Test-Specimen Operating Requirements

Loop and Reactor Operating Requirements

Location and Layout of the Loop Facility

Loop Components

Blower.

Piping.

DESIGN AND CONSTRUCTION OF THE LOOP FACILITY .

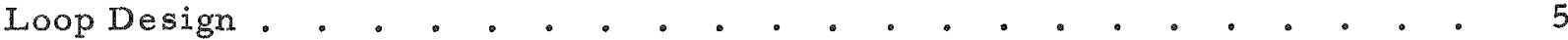

Test Section. . . . . . . . . . . . . . . . . . 9

Cooling System . . . . . . . . . . . . . . . . . . . 9

Blower Assembly

Main Blower

Labyrinth Pump

Oil Pump .

Blower Cask.

Instrumentation and Control

Normal Loop Operation

Safety Features.

Relay System

Low-Level Scram System

High-Level Scram System

Postscram Control

Transfer Equipment

Specimen-Transfer Device

Transfer Cask

Tests of Transfer Equipment and Procedures

Steady-State Operation . . . . . . . . . . . . . . . . . 21

Transient Operation . . . . . . . . . . . . . . . . . 23

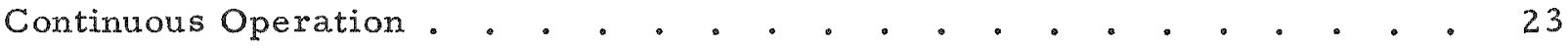

INSTALLATION IN THE REACTOR POOL - . . . . . . . . . . . . . 24

INITIAL IN-PILE OPERATION.$- \quad \cdot \quad \cdot \quad \cdot \quad \cdot \quad \cdot \quad \cdot \quad \cdot \quad \cdot \quad \cdot \quad \cdot \quad \cdot \quad 30$

Performance of the Loop From the Standpoint of Gas Flow and Temperature •. • . . . . . . . . . . . . 30

Procedures for Neutron-Flux Measurements of Loop-Test Specimens . . . 32 GENERAL DISCUSSION OF THE LOOP DESIGN AND PERFORMANCE . • • . 34 


\title{
AN IN-PILE GAS-COOLED LOOP INSTALLED AT THE BATTELLE RESEARCH REACTOR
}

\author{
George T. Bodnar, Wallace J. Stevens, Gerald A. Francis, \\ Sherwood L. Fawcett, and Albert M. Rockwood
}

\begin{abstract}
A developmental program was conducted to provide a loop facility for use in evaluating fuel specimens for gas-cooled-reactor applications. The program included the design, construction, and operation of a recirculating in-pile loop featuring high-pressure gas as the primary coolant. The loop facility was designed for gas pressures of up to 200 psig and gas-flow rates up to $0.415 \mathrm{lb}$ per sec with nitrogen as the coolant. Design features incorporated into the facility included the mounting of the complete "paclage" on the movable bridge at the Battelle Research Reactor $(B R R)$. This provided ease in moving the loop away from the reactor core for service and specimen transfers.
\end{abstract}

The loop design featured an aluminum pressure uall and concentric counterflow gas passages with staticagas insulation adjacent to all pressure ualls. The entire circulating system was located beneath the water level of the pool to provide shielding and simplicity. The blower was designed for use at $750 \mathrm{~F}$ inlel-gas temperabure, and it feabured both oil and water cooling. The instrumentation was designed to protect personnel and equipment, and to provide information on the specimen during irradiation. The specimen-transfer mechanism was designed to utilize pool-water shielding while moving a dry specinen from the loop cask located approximately $20 \mathrm{ft}$ below the pool surfoce.

The complete loop system uras subjected to both out-ofopile and in-pile evaluation. The blower has operated satisfactorily over $2000 \mathrm{hr}$ and specimen transfers have been effecied without water leakage into the loop or transfer cash.

\section{INTRODUCTION}

In the development of fuel assemblies for a new reactor system it is important to evaluate proposed fuel-element designs and materials under conditions which simulate as closely as possible the reactor environment. Specific problem areas in fuel-element development may be studied by such means as capsule irradiations, corrosion tests, thermal-cycling and fluid-flow experiments, etc. Ultimately, however, it is desirable to determine the performance of the element design under the combined effects which will be present in the reactor system. For this purpose in-pile forced-convection loops are a convenient and necessary experimental tool.

In support of the gas-cooled-reactor program of the Army Reactors Branch of the $A E C$, a program was undertaken to design, construct and operate an in-pile loop facility at the Battelle Research Reactor (BRR) for the purpose of evaluating fuel-element 
assemblies for this application. This report describes the design, construction, and the initial operation of this loop facility.

\section{CONCEPTUAL-DESIGN CONSIDERATIONS}

The design of an in-pile-loop facility must take cognizance of (1) the reactor system for which the fuel elements are being developed, (2) the ability to obtain or develop the necessary components for the loop system within practical limitations on time and cost, and (3) the limitations and requirements of the test reactor in which the loop facility is to be installed. These three primary factors are perhaps never completely compatible and many compromises are necessary.

\section{Test-Specimen Operating Requirements}

At the inception of the program neither the specific design criteria of the gascooled-reactor system nor the specific fuel system for this reactor program had been established. Thus it was necessary to assume specifications as to the size and type of fuel-element test specimen, the coolant-gas conditions, and the specimen-power generation. These assumptions lead to the following design specifications pertaining to the test conditions in the loop:

Coolant

Gas pressure

Gas-flow rate

Available pressure head across specimen

Gas temperature

Inlet to the specimen

Outlet from the specimen

Test section size

Heat-removal capacity

Duration of test
Recirculating nitrogen gas with helium as a possible alternative

Ambient to 200 psig maximum

$0.415 \mathrm{lb}$ per sec maximum

5 psi at maximum flow rate

\section{$750 \mathrm{~F}$}

$1150 \mathrm{~F}$ maximum

1. 5 in. ID $\times 24$ in. long

$50 \mathrm{kw}$ maximum

$10,000 \mathrm{hr}$ maximum 
Loop and Reactor Operating Requirements

Safety considerations and adequate experimental measurements required that the loop system be well instrumented for measurements of gas flow, temperature, and pressure, and that it be stable and well controlled in these variables. Also, the system should be leaktight and of minimum gas volume.

From a maintenance and operating standpoint it was desirable to be able to make repairs or replace loop components easily, and remove and insert fuel specimens without affecting the condition of the specimen and loop. In addition, the reactor downtime caused by loop or specimen failure must be an absolute minimum.

These criteria are quite general and applicable in varying degrees to any loop system and test-reactor installation. However, they are mentioned here because they had a direct bearing on the concept of this loop system.

\section{Location and Layout of the Loop Facility}

The BRR is a modified pool reactor licensed for operation at 1 megawatt. The reactor core is supported from a movable bridge. The core is normally operated at one end of the pool. In this location one vertical face of the core is adjacent to a thermal column, and two faces are adjacent to six beam tubes. The remaining vertical face is open to the pool. The reactor pool is divided by a movable gate to permit draining the back pool while keeping the core submerged. A separate movable bridge is available for experimental purposes.

The size of the test section and the operational requirements of the BRR dictated that the test section be located vertically at the open core face immediately adjacent to the core. Two possibilities suggested themselves as to the location of the remaining loop components:

(1) Alongside the pool at the pool-surface floor level.

This axrangement would require the loop piping to come to the pool surface. Shielding would be required against a test specimen failure which released fission products throughout the loop system. Furthermore, the loop components outside the pool would have to be enclosed in a gastight envelope which could be vented to the stack in a controlled fashion.

In addition to the shielding and gas-contamination factors, the test section would have to be fixed at the core location. Consequently, reactor operation independent of a loop component or specimen failure would require at least duplicate blowers, heat exchangers, etc., in the loop system. 
(2) Arranged in a movable "package" and submerged in the pool.

This scheme appeared to have advantages in flexibility and simplicity since the entire loop system could be moved away from the reactor core for maintenance and specimen transfer. Also, the total gas volume of the system could be minimized - a desirable feature from the standpoint of gas-system contamination. It had the disadvantage of making the system components relatively inaccessible even to minor repairs.

The package loop could be supported on a movable bed resting on the pool floor or suspended from the experimental bridge. In either event the loop layout would have to be capable of passing through the gate of the reactor pool.

After study of these possibilities it was decided to pursue the concept of a packaged loop suspended from the experimental bridge.

\section{Loop Components}

Having committed the loop design to the submerged-package concept, it was desirable to minimize the number, size, and complexity of the loop components. The cost of the loop system and the time schedule for its completion also favored this direction. Accordingly, the loop system was visualized as comprizing the test section, a heat exchanger, and a blower with the necessary control and instrumentation. A preheater was not included since preliminary heat-loss calculations indicated that the desired gas temperatures could be maintained by the specimen-power generation (as will be discussed later, the heat losses turned out to be higher than initially predicted). Regeneration (an economizer) was not included, per se, also in the interest of space and simplicity.

\section{Blower}

Since a preheater and an economizer were not provided in the design, the blower was required to be capable of operation with high-temperature gas. The design gas temperature chosen was $750 \mathrm{~F}$.

A survey of the existing technology and commercial availability of hightemperature blowers, shaft seals, and bearings led to the following conclusions:

(1) No commercially available blower would meet the requirements of this application.

(2) Reliable shaft-seal materials and designs for nitrogen at these temperatures and pressures were not known.

(3) Existing gas-bearing technology did not indicate that gas bearings could be utilized with confidence under these conditions. 
These considerations led to the decision to design a blower which was completely canned in the coolant gas, and which contained oil-lubricated bearings.

\section{Piping}

Neutron economy in the test-section region favored the idea of utilizing cold pressure walls of aluminum, a. static gas annulus for insulation, and thin high-temperature ducting within. This design scheme was used throughout the loop piping system. In addition, it appeared desirable to run the inlet and exit gas streams coaxially wherever possible to gain some inherent regeneration. This arrangement also permitted the use of slip joints in the high-temperature ducting - a factor which eliminated thermal-stress and distortion problems.

\section{DESIGN AND CONSTRUCTION OF THE LOOP FACILITY}

\section{Loop Design}

A schematic longitudinal section of the loop assembly is shown in Figure 1 . Figure 2 shows a photograph of the loop assembly prior to installation in the reactor pool.

As shown in Figure 1 , gas flows from the blower to the diffuser section and then through an orifice plate for flow-rate measurement. After leaving the orifice-plate assembly, the flow is diverted into an annulus formed by two concentric tubes and thence to the bottom of the test section. The coolant then passes up through the test specimen, leaving the test section through the center tube. The flow continues through the center tube past the flow-control valve, through the heat exchanger, and then on to the blower.

Inconel pipes are used in the primary-loop system to contain the hot gases. The Inconel pipes, in turn, are contained in aluminum pipe which serves as a pressure wall. The annular space between the Inconel pipes serves as the supply passage to the test specimen. The annular space between the outer Inconel and the aluminum pressure wall contains static gas at loop pressure. This gas acts as an insulator to reduce the heat losses from the loop and to hold the aluminum pressure walls at a reasonably low temperature. A view of the tube arrangement is shown in Figure 3.

The relief of thermal stresses in the Inconel pipe by the use of expansion joints did not appear feasible in the confined space within the pressure wall. Since any type of mechanical expansion joint would have resulted in restrictions in the flow area, slip joints were incorporated in the design at all 90-deg turns and at all flanged connections. The slip joints are $1 \mathrm{in.}$ long and have a clearance of $0.005 \mathrm{in}$. on the diameter.

The materials selected for use in the loop piping were Inconel for the internal flow path and aluminum for the pressure wall. Inconel was selected rather than stainless steel because of its ability to resist nitriding at higher temperature. The selection of aluminum for the pressure walls was based on two considerations: (1) power attenuation. in the test section, and (2) weight. The ratio of flux attenuation between aluminum and stainless steel, using the same size pipe, is of the order of 0.95 to 0.63 . If stainless 


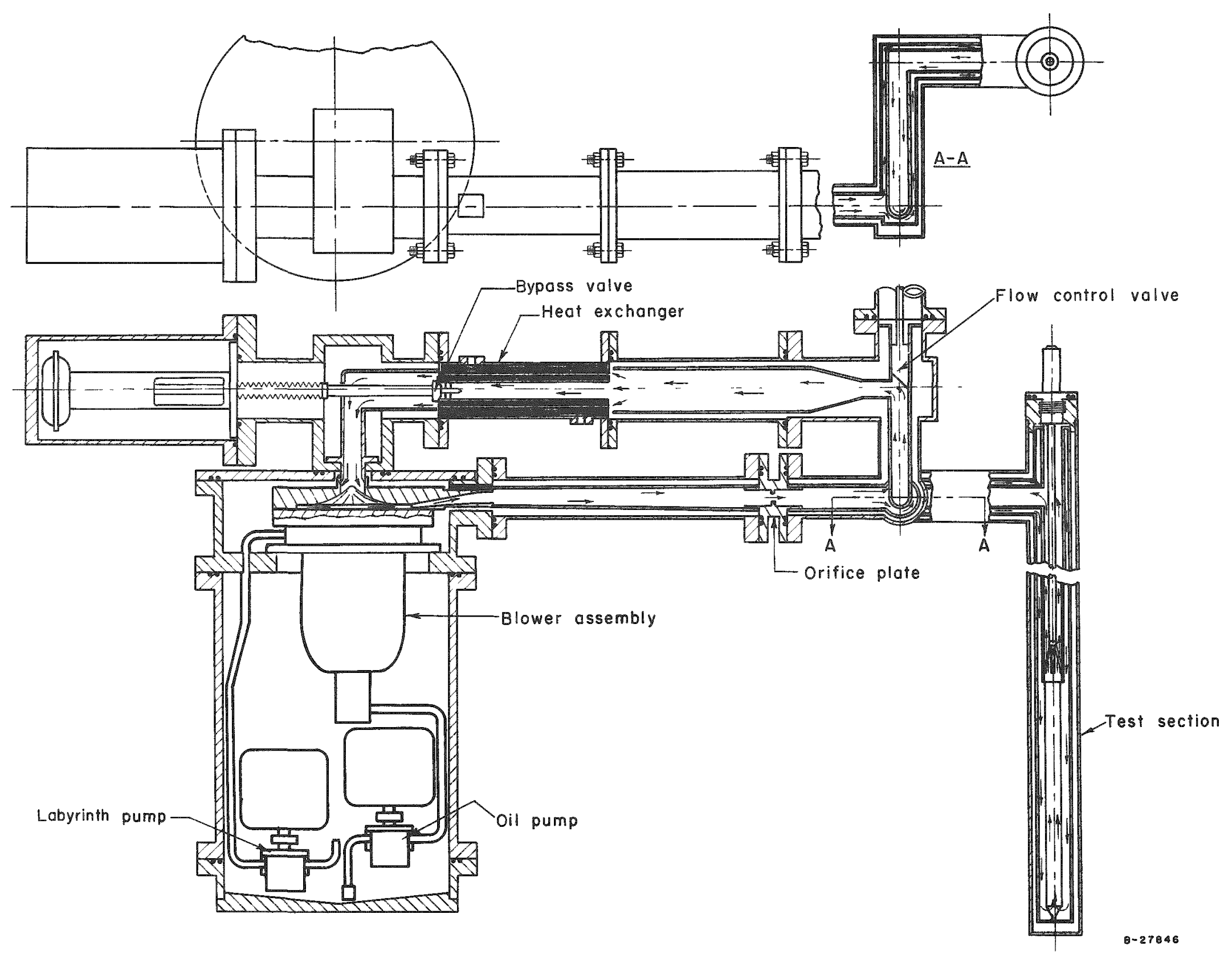

FIGURE 1. LONGITUDINAL SECTION OF LOOP ASSEMBLY 

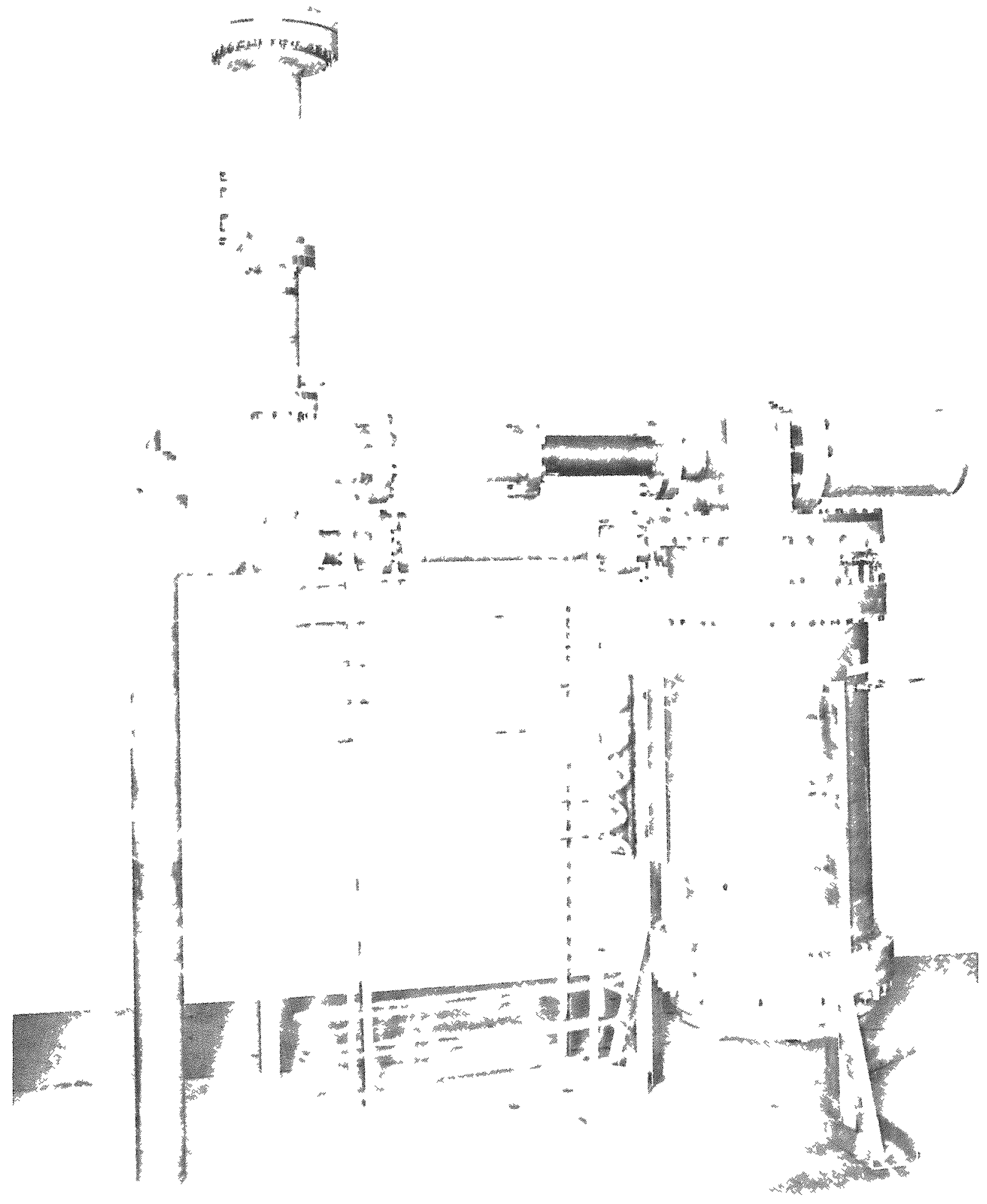

N47508

FIGURE 2. SIDE VIEW OF LOOP ASSEMBLY 


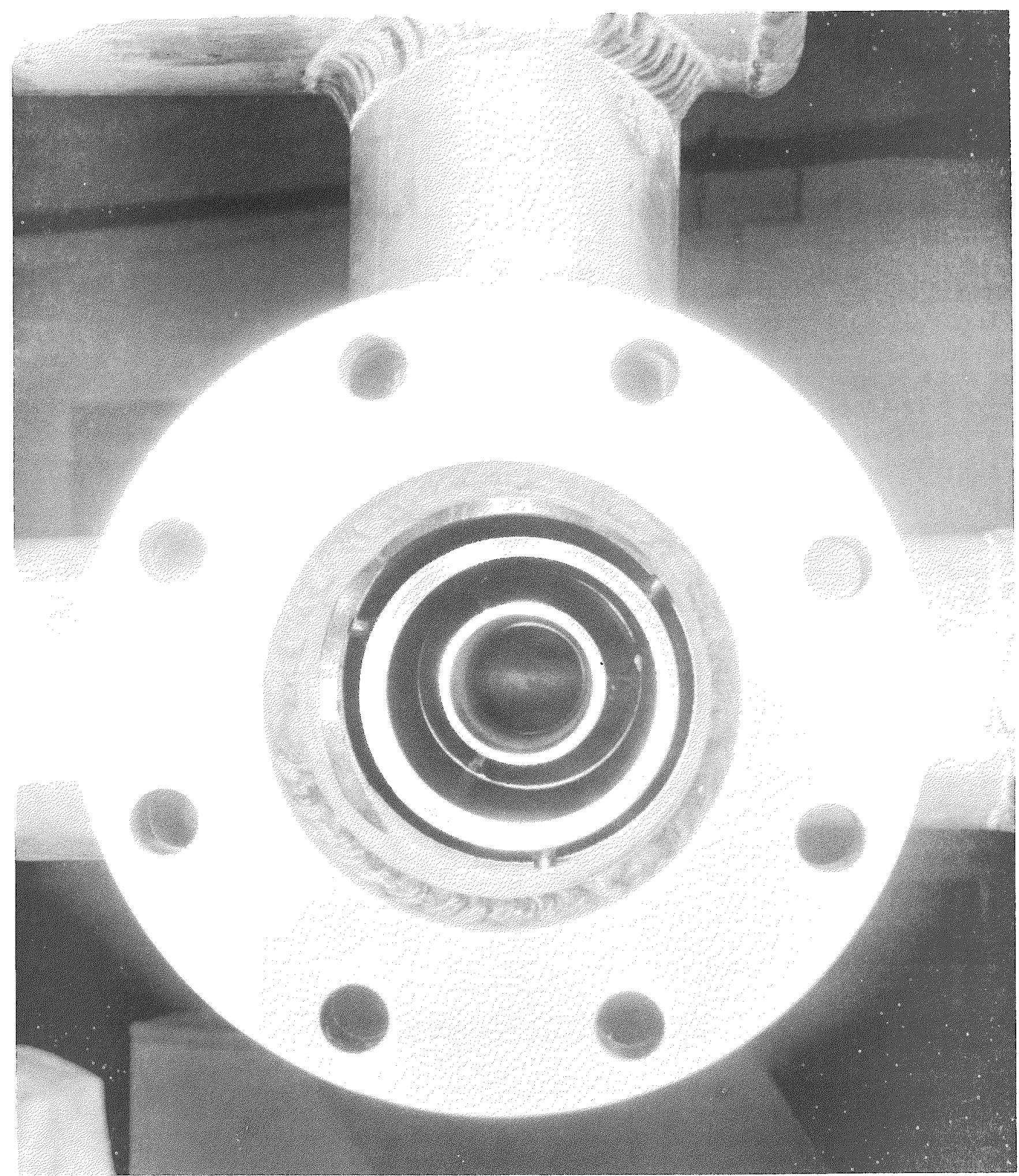

N 38674

FIGURE 3. CONCENTRIC-TUBE ARRANGEMENT IN LOOP PIPING 
pipe had been used for the pressure wall a decrease in power of approximately 30 per cent would have resulted. A saving in the weight of the pressure-wall piping was achieved by the use of aluminum pipe.

All flanged connections in the loop as sembly are sealed with stainless steel selfenergizing $\mathrm{O}$-rings backed up by rubber O-rings of a formulation suitable for this application. The metal $O-r i n g s$ are made from 1/8-in. OD by $0.010-i n$. wall Type 321 stainless steel tubing. The self-energizing feature is accomplished with holes drilled. at the inside diameter of the $\mathrm{O}-\mathrm{ring}$. These holes act as vents to allow the pressure being sealed to get inside the tube and prevent collapsing of the tube. An unbalance of forces then exists across the sealing surface to increase the resilience of the O-ring. A Buna $S$ compound was selected for the rubber O-rings. This material was selected on the basis of its resistance to radiation damage and its performance in oi1, water, and nitrogen at temperatures up to $260 \mathrm{~F}$. Heat-transfer calculations showed that temperatures at the rubber 0 -rings will be from 160 to $180 \mathrm{~F}$.

\section{Test Section}

The test section which houses the test specimen consists of three vertical concentric tubes. The outermost tube is made from standard 4-in. aluminum pipe and provides the pressure wall. The outside diameter of the pipe is $4.500 \mathrm{in}$. and the wall thickness is 0.237 in. The two inner tubes are made from standard 2- and 3-in. Inconel pipe machined to a 1/16-in. wall thickness. These inner tubes form the passages for conducting the gas to and from the test specimen. The coolant flows to the test specimen through the annulus created by the two Inconel tubes and then returns to the heat exchanger through the inside tube. The test specimen is located in this center tube. The annular space between the outer Inconel tube and the aluminum pressure wall contains static gas.

\section{Cooling System}

The secondary cooling system is a closed water loop consisting of the water pumps, the gas-water heat exchanger, and cooling coils for exchange of heat to the reactor pool water.

Two cast iron turbine-type water pumps are connected in parallel in the secondary cooling system. Either unit will supply a maximum of 10 gal per min of cooling water to the heat exchangers. One unit is for stand-by use but it can be connected in series with the other unit to boost the water flow if necessary.

The heat exchangex is of shell-and-tube construction consisting of twenty-four 3/16 in, - ID cooling tubes and one 1-1/2-in.-diameter bypass tube contained in a watercooled shell. The amount of heat removed from the gas is controlled by a pneumatic diaphragm-actuated valve on the bypass tube which controls the flow of cooling gas through the tubes. The heat exchanger is approximately $13 \mathrm{in.}$ long.

The cooling coils are composed of $80 \mathrm{ft}$ of $3 / 4-\mathrm{in}$. -OD by $5 / 8-\mathrm{in}$. -ID aluminum tubing. The coils are mounted below the horizontal piping of the loop as shown in Figure 1. Water leaving the heat exchanger passes through the cooling coils, to the blower assembly, where it passes through the lower blower housing. The cooling water then passes to the storage tank on the instrument bridge for return to the heat exchanger. 
Blower Assembly

The blower assembly is composed of four components: the main blower, the oil pump, the labyrinth pump, and the blower cask.

Main Blower

The main blower is designed to operate at 10,000 $\mathrm{rpm}$ and to deliver approximately $0.415 \mathrm{lb}$ per sec of nitrogen at a pressure of $200 \mathrm{psia}$ and $750 \mathrm{~F}$ against a head of 10 psi. The main blower, shown in Figures 4 and 5 has a 5 -hp motor mounted on a common shaft with the impeller. The impeller is cast and machined from an ASTM A297 (AC1-HT) heat-resistant alloy.

The impeller, armature, and shaft are supported by two sets of oil-lubricated bearings. The upper bearing consists of a duplex set of precision angular contact bearings. The lower bearing is a precision floating-type bearing. The bearing temperatures are maintained at a safe level by cooling water which passes through the upper blower housing and oil which circulates through a stationary tube to the top of the shaft and flows back to the sump. Oil is directed to the bearings by two methods. Lubricating jets in the shaft supply oil by centrifugal force and a secondary force-feed system supplies oil through the bearing housing.

A labyrinth-type seal is used between the blower impeller and the upper set of bearings to prevent oil from entering the primary-loop system. The oil leakage is further restricted because the oil in the upper bearing is forced to flow down through the bearing or out by centrifugal force at the top of the bearing. The oil leaving the top of the bearing is collected under a bearing cover and drained through the bearing housing to a collector plate. This plate allows the oil to drain out of the motor housing and back to the sump. The effectiveness of this system is augmented by the labyrinth pump which will be described below.

\section{Labyrinth Pump}

The labyrinth pump is a gear-type pump capable of delivering $1 \mathrm{gpm}$. The pump is mounted partially submerged in the oil sump with the discharge line terminating above the pump-discharge outlet. This insures that oil will always remain in the pump during periods of shutdown. The suction side of the pump is connected to the top of the outer labyrinth seal. Any liquid oil that may be transferred to the top of the seal by differential pressures is drawn down the outside of the outer seal through 12 longitudinal grooves to the circumferential groove in the lower blower housing and thence to the pump which discharges the oil into the cask.

\section{Oil Pump}

The oil pump is an 11 gpm gear-type pump driven by a l-hp motor. The pump takes oil from the 5-gal sump and delivers it to the stationary tube of the main blower. A small portion of the oil is diverted to the force-feed system for bearing lubrication. 


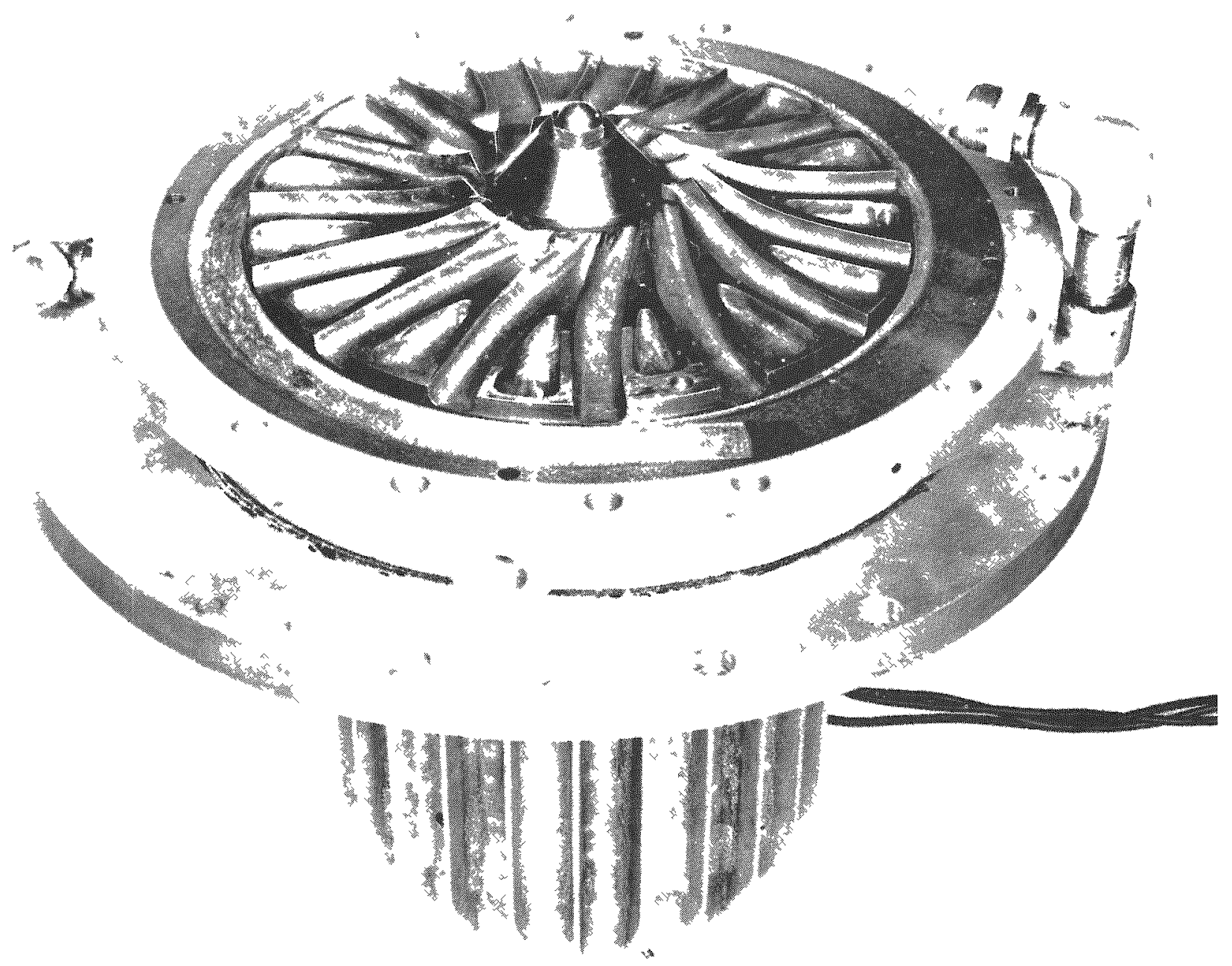

N47457

FIGURE 4. MAIN-BLOWER ASSEMBLY 


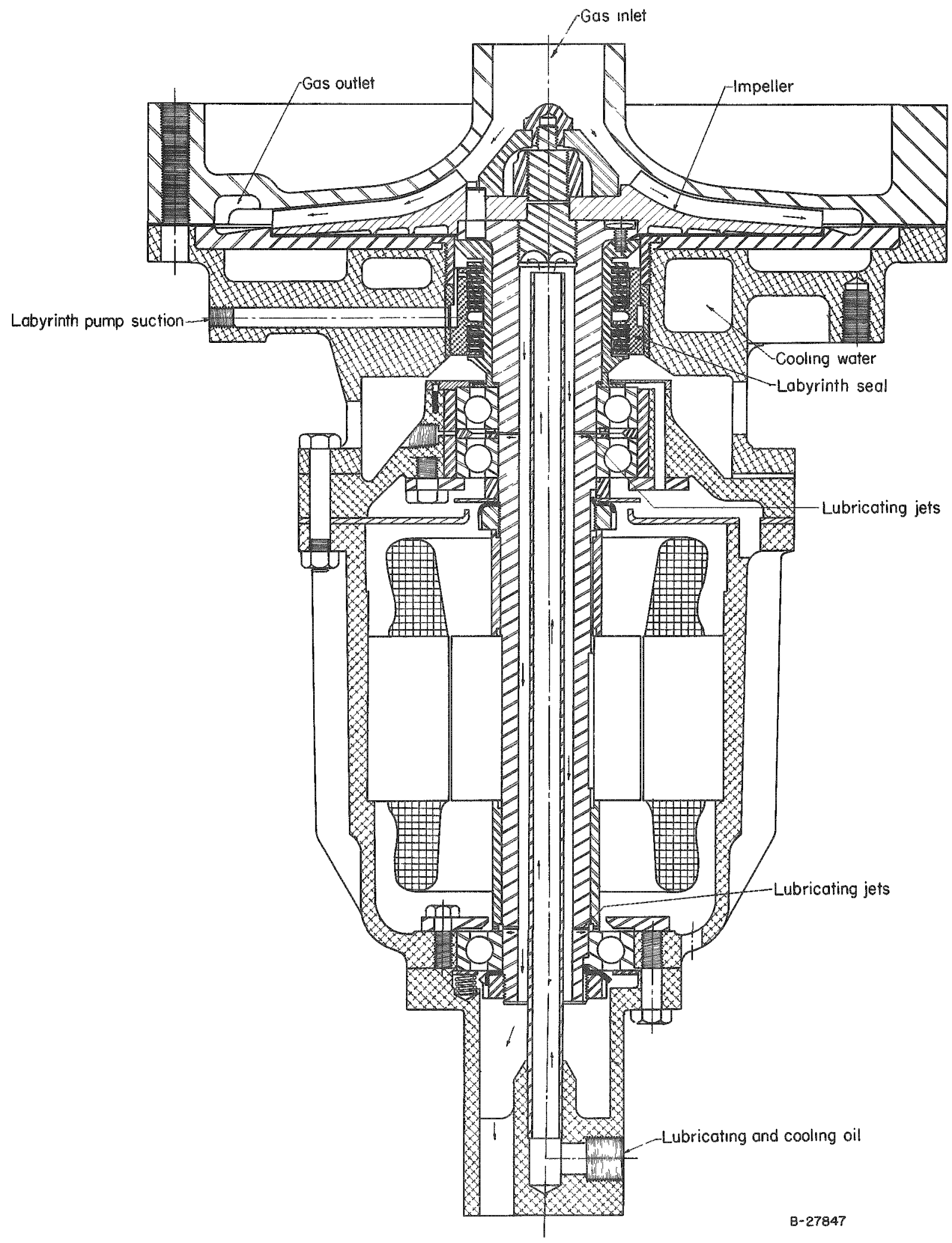

FIGURE 5. SECTION OF MAIN-BLOWER ASSEMBLY 


\section{Blower Cask}

The blower cask is approximately $21 \mathrm{in}$. in diameter and $42 \mathrm{in.}$ long. The cask is made from 6061-T6 aluminum with 2-in. -thick flanges, and it contains the double O-ring seal used in the loop piping. A 5 -gal sump is located below the lower flange of the cask.

\section{Instrumentation and Control}

Instrumentation has been provided to measure and record pertinent loop conditions during operation and to provide the control necessary to insure safe operation of the system. The functions of the instrumentation are divided into normal loop operation, the safety features, and postscram control. A schematic of the instrumentation piping is shown in Figure 6, and a schematic wiring diagram is shown in Figure 7 .

\section{Normal Loop Operation} functions:

During normal operation of the loop, the instrumentation performs the following

(1) Continuously records the temperature at a point in the fuel-test specimen and controls the loop-system temperature from that point. The control feature automatically positions the heatexchangex bypass valve.

(2) Continuously records any two temperatures on two single-point disk-type recorders.

(3) Records any two preselected temperatures using two points on a multipoint recorder.

(4) Records the temperatures in the main blower upper and lower bearings using four points on the multipoint recorder.

(5) Indicates any twelve selected temperatures on a temperature indicator which incorporates a twelve-position selector switch. Normally included in the twelve selected are the following temperatures:
(a) Blower-inlet gas
(b) Blower-outlet gas
(c) Inlet gas to the heat exchanger.

(6) Continuously indicates and controls the gas pressure.

(7) Continuously indicates the gas-flow rate. 
(8) Continuously monitors the gas-stream activity in a bypass line which circulates gas from the blower outlet back to the blower inlet.

(9) Permits manual control of the gas-flow rate.

(10) Permits sampling of the gas in the bypass line as required.

\section{Safety Features}

The operation of the loop system is controlled so as to protect personnel, protect the test specimen, and protect the loop equipment. The loop safety system includes two groups of electrical relays. Any one of the relays can initiate the reduction to zero of power generation in both the reactor and specimen. One group of relays, referred to as the low-level scram system, is designed to maintain gas flow during and after any malfunction of loop components or a reactor scram. A second group of relays, referred to as the high-level scram system, is provided to protect the main blower assembly from damage which would result from excessively high bearing temperatures, loss of lubrication, and the loss of cooling water. In the second case the blower is stopped, since blower protection is more important than specimen cooling after a reactor scram.

Relay System. The reactor power-reduction system is based on the use of a normally open relay in conjunction with each control device. As each control point comes within the normal operating range, the associated relay is energized. A relay is connected in similar fashion to each item of accessory equipment. Thus, all of the control relays are energized while the loop is operating in a normal manner. Whenever any of the control points gets out of range or there is a malfunction in the system or loss of power to any of the components, one or more of the control relays will open. One set of normally open contacts on each relay is connected in series with a set on each of the other relays and with the coil circuit of the main control relay. Thus, whenever one of the control relays becomes de-energized, the power to the main control relay is interrupted and it is de-energized. This will scram both the loop and the reactor.

The control points are so interrelated and the accessory equipment so interlocked that any malfunction of the system or equipment will indirectly affect several relays. Thus, the system provides multiple protection in all critical areas. Except for the remote possibility of the main relay failing to open when its coil is de-energized, the system is essentially failproof. This one possibility, even though remote, is minimized by the use of two relays for this primary function.

An indicating system featuring lights shows which control points are out of operating range and indicates the loss of power to any of the accessory components. An. electric clock is connected in parallel with each control relay. The clocks are started and will run during periods of normal operation. The cause of a system scram can then be determined by an analysis of the elapsed time accumulated on each of the clocks.

Low-Level Scram System. Any of the following events will initiate a low-level $\operatorname{scram}$ (scram reactor and let loop blower run):

(1) A reactor scram for any reason

(2) Loss of power to the 10op instrumentation 


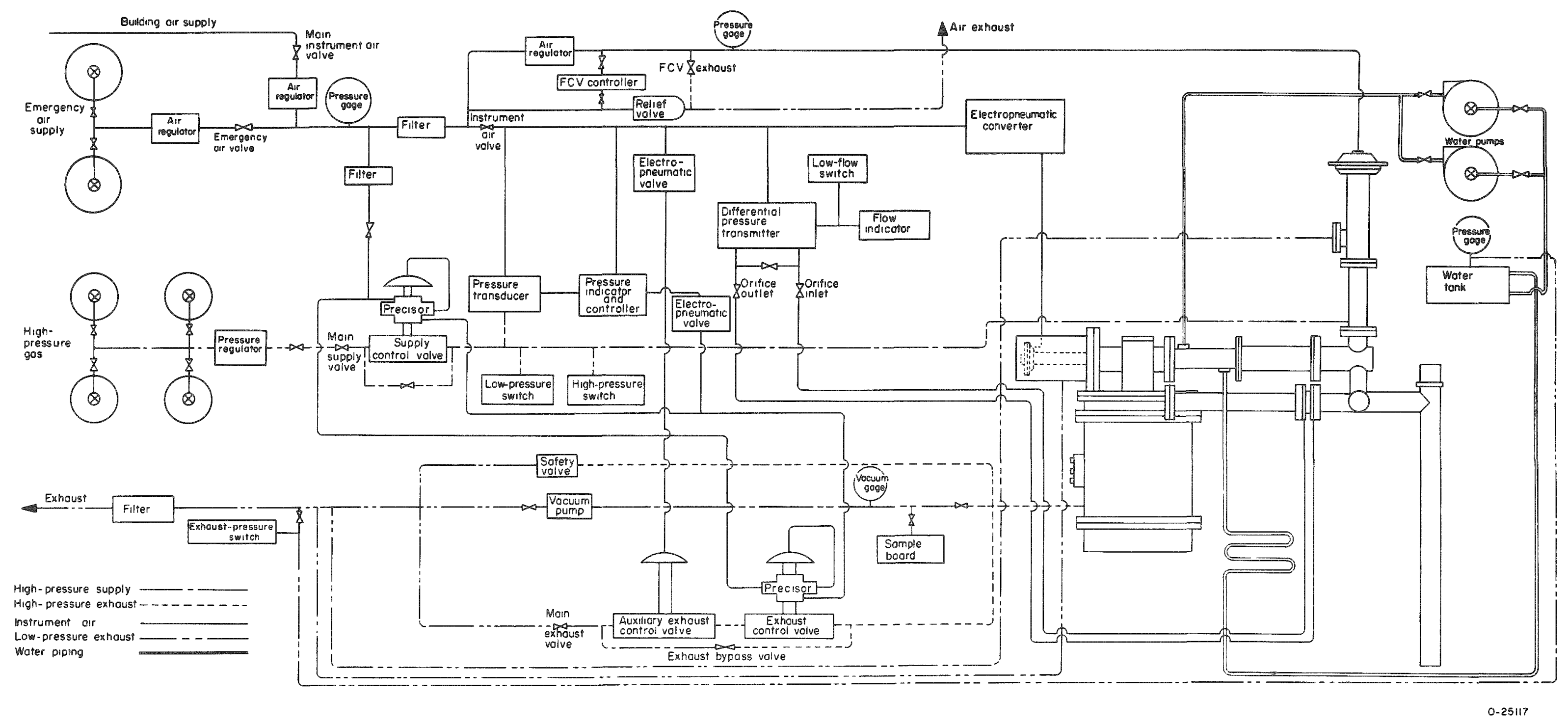

FIGURE 6. SCHEMATIC DIAGRAM OF INSTRUMENTATION PIPING 


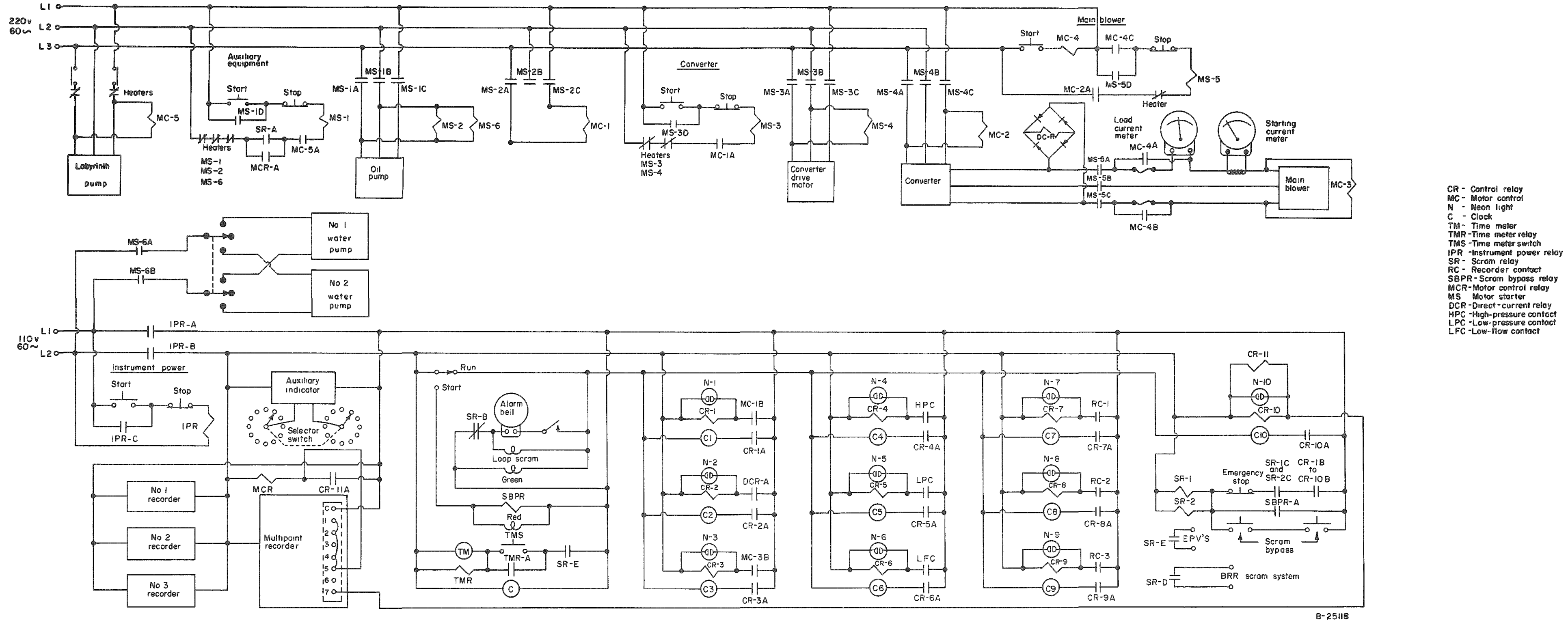

FIGURE 7. SCHEMATIC WIRING DIAGRAM OF CONTROL AND SCRAM SYSTEM 
○. . . 
(3) Loss of instrument air pressure

(4) High blower-bearing temperatures (approximately $300 \mathrm{~F}$ )

(5) A change of more than 10 psi in normal loop operating pressure

(6) Loss of coolant-gas flow (below 50 per cent of normal flow)

(7) Test-specimen inlet-gas temperatures $150 \mathrm{~F}$ above normal

(8) Test-specimen outlet-gas temperatures $150 \mathrm{~F}$ above normal

(9) Test-specimen surface temperatures $150 \mathrm{~F}$ above normal on any of the three thermocouples.

High-Level Scram System. The high-level scram system is designed to protect the main blower assembly from serious damage. The following events will initiate a high-level scram (scram reactor and stop loop blower):

(1) Loss of electrical power to the lubricating-oil pump, water pumps, or labyrinth pump

(2) Loss of electrical power to the frequency-converter drive motor

(3) Loss of excitation to the converter

(4) Loss of 180-cycle power to the blower motor

(5) Blower-bearing temperatures above $350 \mathrm{~F}$.

\section{Postscram Control}

The instrumentation system is designed to perform certain functions after any loop and reactor scram. When a low-level scram occurs, the instrumentation will:

(1) Scram the Battelle Research Reactor

(2) Sound an alarm and light a warning light

(3) Close the system gas - supply valve

(4) Close the system exhaust valve

(5) Indicate the cause of the scram (if caused by the loop system).

When a high-level scram occurs, the instrumentation system will shut off the blower in addition to performing the functions listed for a low-level scram. 


\section{Transfer Equipment}

The location of the loop assembly under approximately $20 \mathrm{ft}$ of water in a pooltype reactor required the design of special equipment for the loading, unloading, and storage of the irradiated test specimens. A specimen-transfer device and a lead storage cask were designed and constructed for this purpose.

\section{Specimen-Transfer Device}

The transfer device is designed to load and unload test specimens dry under approximately $20 \mathrm{ft}$ of water and to transfer specimens to a lead cask for safe storage and handling.

The device consists of a pressurized air bell equipped mechanically to perform these functions. The device is approximately $24 \mathrm{ft}$ long. The air-bell part of the mechanism consists of $7 \mathrm{ft}$ of 5 -in. aluminum pipe with a rubber seal on the open bottom. The top end contains rubber $\mathrm{O}$-rings for sealing the test-specimen operating rod. A second rod is positioned on the outside of the air bell for removal and insertion of the plug which seals off the loop after a test specimen has been removed. This rod enters an enlarged section at the lower end of the air bell through rubber O-ring seals. This enlarged section houses the dummy plug and contains the mechanism for positioning and rotating the plug as it enters the test section. The complete mechanism is suspended from the reactor-building crane and is oriented so that the air bell can be lowered alongside the instrument bridge over the vertical leg of the test section. When in position to effect a transfer, a rubber seal at the bottom of the air bell rests in a grooved flange on the test section. A hose supplies air to the bell to maintain sufficient pressure to keep water from entering the bell during a transfer.

\section{Transfer Cask}

The transfer cask was designed for storage of the test specimen under water and for its safe removal to the hot-cell facilities. The top of the cask has the same construction as the test section. A removable stainless steel container is secured in the cask with a steel pin for ease of replacement. The cask is approximately 25 in. in diameter over most of its length and tapers down to $10 \mathrm{in}$. in diameter at the top. The outer and inner walls are made of stainless steel with $10 \mathrm{in}$. of lead in between for shielding.

\section{Tests of Transfer Equipment and Procedures}

Extensive dry and wet transfer tests were conducted between the transfer mechanism and the storage cask to perfect a safe method for loading and unloading specimens and to familiarize personnel with the use of the equipment. The dry transfer tests were conducted out of the pool between the transfer mechanism and a dummy test section. Minor modifications were made to the mechanism and the tests continued between the mechanism and the storage cask using a dummy test specimen. During the tests, approximately six successful transfers were conducted. The wet transfer tests were conducted in the reactor pool between the mechanism and storage cask. A very slight amount of moisture accumulated in the storage cask during these tests. 
A new specimen can be handled safely out of water but once a specimen has been irradiated in-pile, it must be handled underwater thereafter. A new specimen can be loaded into the transfer mechanism out of the pool. The transfer device is then lowered into the pool and maneuvered into position until a seal with the test specimen is effected. By means of three mechanical devices, the plug at the top of the test section is unscrewed and moved out of the way. The test specimen is then lowered into position in the test section and the threaded plug at the top of the specimen-support rod is screwed into mating threads in the test section until a seal is insured. The transfer device is then withdrawn and the loop prepared for operation.

To unload a test specimen, the pressure within the loop is reduced and the transfer mechanism is lowered into the pool and positioned on the test section. When a seal is insured, the test specimen is unscrewed and withdrawn from the chamber. A plug is then inserted in the test section to seal out the water. The hot specimen is then loaded into the storage cask in the same manner in which it was originally loaded into the loop test section.

\section{OUT-OE-PILE SHAKEDOWN TESTS}

An out-of-pile test program was set up to simulate reactor operating conditions. A water tank, $8 \mathrm{ft}$ in diameter and $10 \mathrm{ft}$ high was constructed for these tests. A $50-\mathrm{kw}$ electric heating element, similar in configuration to a test specimen, was used to supply the necessary power. The out-of-pile test program provided an opportunity to study the system behavior under varied operating conditions, and to gain experience in performing routine operations. The test consisted of steady-state, transient, and continuous operation.

\section{Steady-State Operation}

Tests were first run with air at atmospheric pressure to obtain data for an analysis of blower performance and to check the behavior of the bypass and flow-control valves and auxiliary equipment. These tests were repeated at 10, 30, and 60 psig. All of the equipment and valves performed satisfactorily during these initial tests. Small amounts of power were then applied to the heating element to check temperatures and flow rates. At $4 \mathrm{kw}$ the outlet-gas temperature showed a change of $100 \mathrm{~F}$ for full travel of the flow-control valve at a loop pressure of 60 psig. Power was then increased to $10 \mathrm{kw}$. The equipment continued to function properly under the new conditions. Data taken in these tests were used to calculate blower performance at design conditions. The curve shown in Figure 8 is the result of these calculations and shows the design point taken from the original design calculations.

Further tests were made with nitrogen and pressures increased to 140 and 185 psig. The performance of the loop was then checked at these pressures with an electrically heated element from a minimum power of $4 \mathrm{kw}$ up to a maximum of $25 \mathrm{kw}$. Approximately $120 \mathrm{~F}$ of temperature control was obtained from the heat-exchanger bypass valve at an element power of $25 \mathrm{kw}$. 


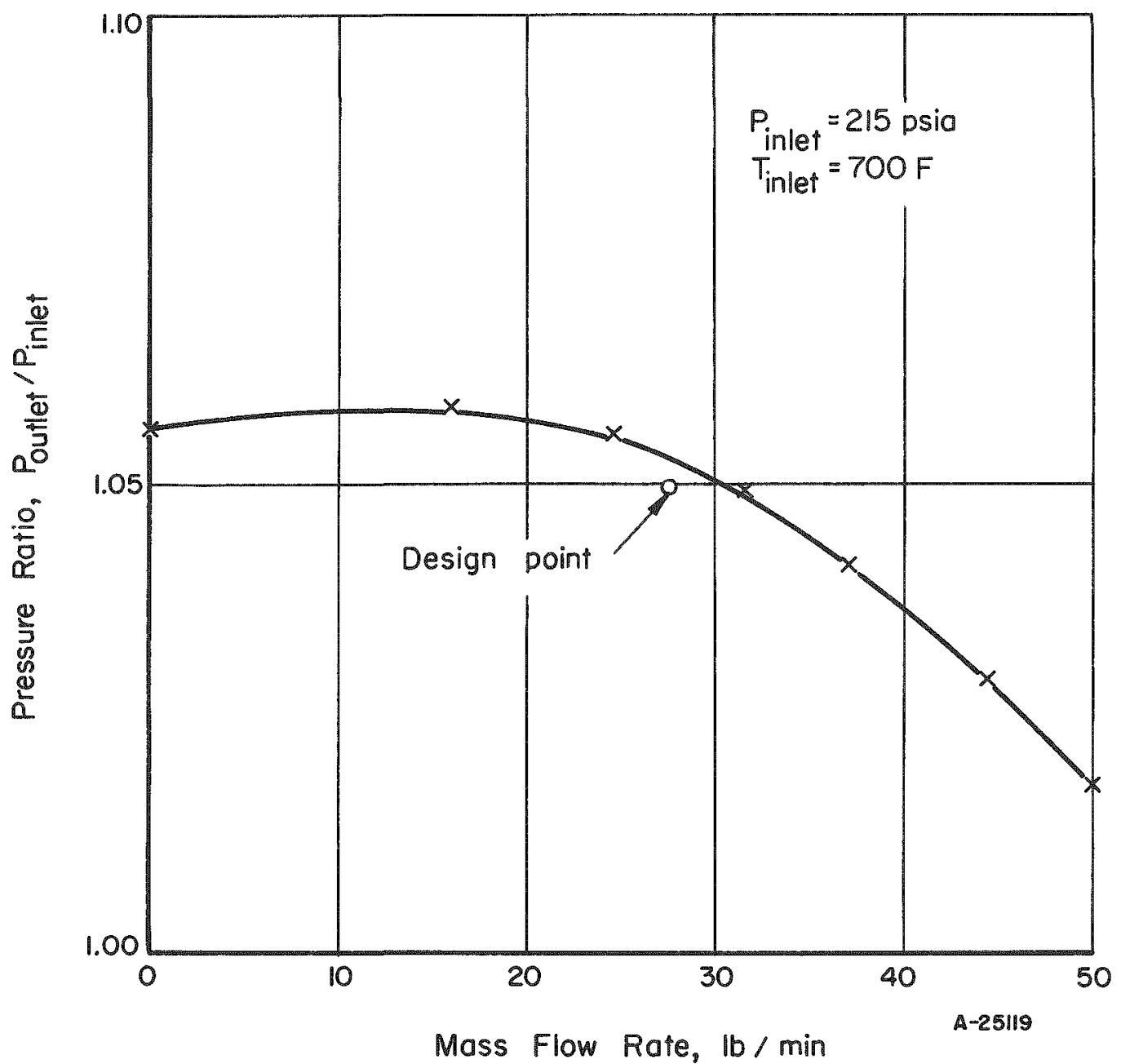

FIGURE 8. CALCULATED BLOWER PERFORMANCE 


\section{Transient Operation}

The purpose of these tests was to observe the effect of 10 per cent changes in power to the heating element and the effect of power changes from zero to full power and full power to zero. The 10 per cent power-change tests were run in the 22 to $25-\mathrm{kw}$ power range. The tests revealed that the automatic temperature-control system would not hold the loop temperatures at a constant level following a reactor power change of this magnitude. Calculations, based on experimental data, indicated instead that the effectiveness of the automatic control system would be limited to power changes of about 5 per cent. A power change greater than 5 per cent is not considered unsafe, since the safety features built into the instrumentation would cause the reactor to shut down if the automatic control system were to become ineffective. However, since the reactor power seldom changes more than 1 or 2 per cent in normal operation, the control system was considered adequate.

The zero-to-full power $(26 \mathrm{kw})$ tests were conducted to simulate the startup procedure normally used at the reactor. The startup from $4 \mathrm{kw}$ to $26 \mathrm{kw}$ was made in 3 min. Adjustment of the loop pressure and flow-control valve provided a safe normal startup. The full power-to-zero tests showed a rapid drop in loop test-section temperatures from $1150 \mathrm{~F}$ to $400 \mathrm{~F}$.

Tests were also conducted at normal loop operating conditions to simulate malfunctioning of the loop components. The following conditions were investigated:

(1) Electric-power failure

(2) Recorder-controller failure

(3) Loss of coolant flow

(4) Pressure changes of plus or minus 10 psi

(5) Alternator failure

(6) Cooling-water-pump failure

(7) Outlet-gas temperatures $150 \mathrm{~F}$ above normal

(8) Inlet-gas temperature $150 \mathrm{~F}$ above normal

(9) Bearing temperatures above $300 \mathrm{~F}$.

All of the above tests resulted in a scram of the loop with a resultant scram of the heating element which represented the reactor.

\section{Continuous Operation}

A number of continuous tests were undertaken as a final check on loop performance. The duration of these tests varied because of oil contamination in the loop. The gas was sampled periodically to determine the nagnitude of the oil contamination. 
Tests $83.2,89.3$, and $89.5 \mathrm{hr}$ in duration were run. These tests were run at a $25-\mathrm{kw}$ input from the heating element and a loop pressure of 185 psig. Samples of the gas in the first run showed an oil content of $250 \mathrm{ppm}$. The oil contamination in the second test was reduced to $212 \mathrm{ppm}$ through the addition of the labyrinth pump to the blower assembly. A further reduction to 21 ppm was effected during the last run by changes in a portion of the top of the outer labyrinth seal and by restricting the flow of oil out the top of the upper blower bearing. A summary of the loop running time during the out-of-pile tests appears in Table 1.

TABLE 1. SUMMARY OF OUT-OF-PILE LOOP RUNNING TIME

\begin{tabular}{cc}
\hline Conditions of Operation & Test Time, $\mathrm{hr}$ \\
\hline Atmospheric & 312.6 \\
Under $20 \mathrm{kw}$ & 48.5 \\
Over $25 \mathrm{kw}$ & 19.0 \\
At $25 \mathrm{kw}$ & 265.3 \\
Total time & 645.4 \\
\hline \hline
\end{tabular}

Examination of the inside of the loop system after the last run showed no evidence of oil contamination. Furthermore, estimates of the minimum oil content in the gas owing to vapor pressure indicated that this amount of oil was about as low as could be expected.

\section{INSTALLATION IN THE REACTOR POOL}

The general arrangement of the loop assembly in the reactor pool is shown in Figures 9 and 10. The top of the test section is located approximately $18 \mathrm{ft}$ below the surface of the water. The weight of the loop assembly is supported by a structural aluminum frame which is fastened to the main beams of the experimental bridge and bolted to the loop as sembly. The aluminum support tower is constructed in three sections to facilitate installation and removal of the loop assembly from the reactor pool. Aluminum tubing and tube fittings were used for all the lines between the loop assembly and the instrumentation. The in-pile installation is shown in Figures 11 and 12 . The movable instrument bridge and instrumentation are shown in Figure 13.

Work on the installation was restricted to normal shutdown days at the reactor when the gates separating the front and back pool were lowered into position and the water in the back pool was pumped to a storage tank. 


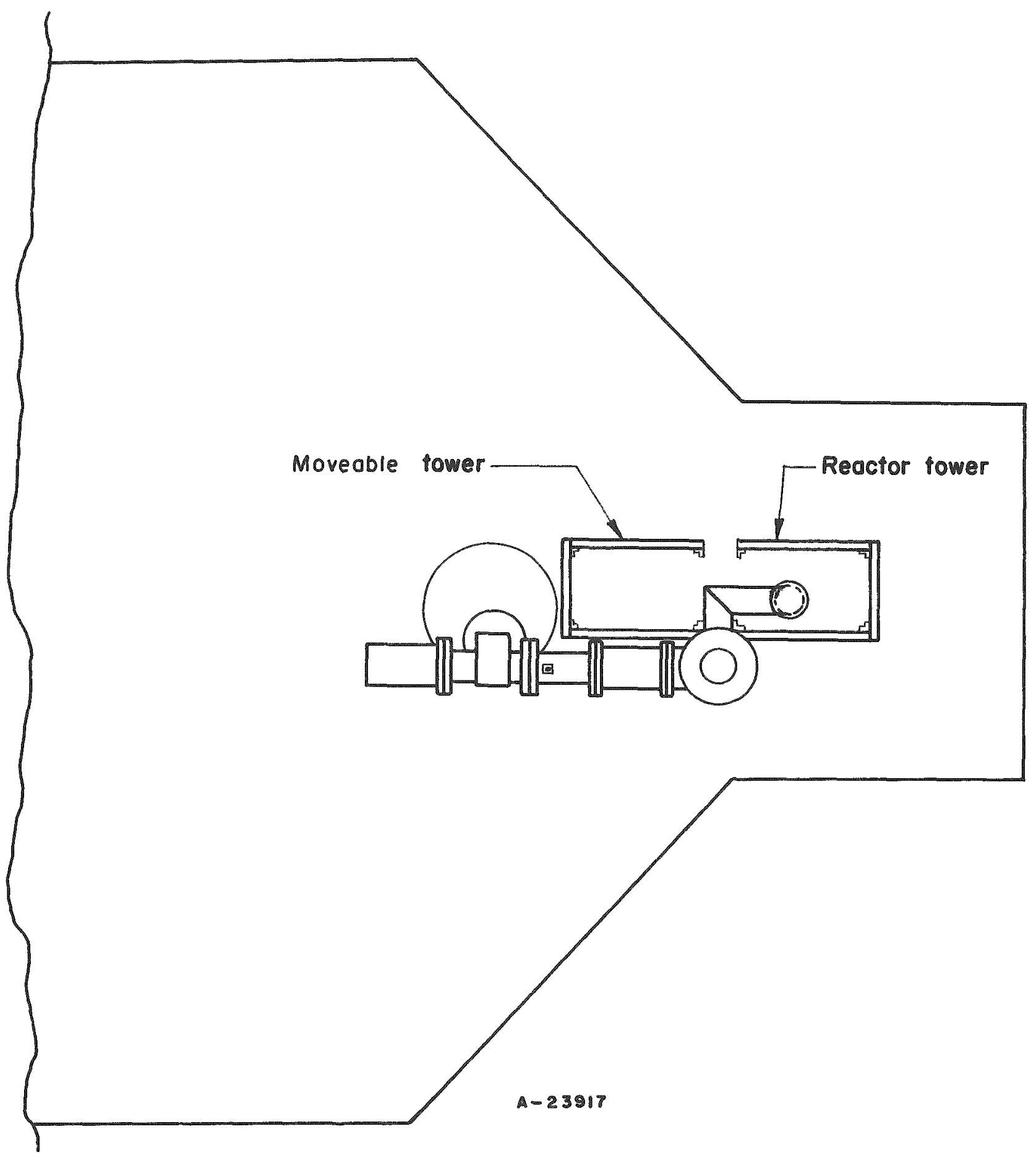

FIGURE 9. TOP VIEW OF LOOP IN REACTOR POOL 


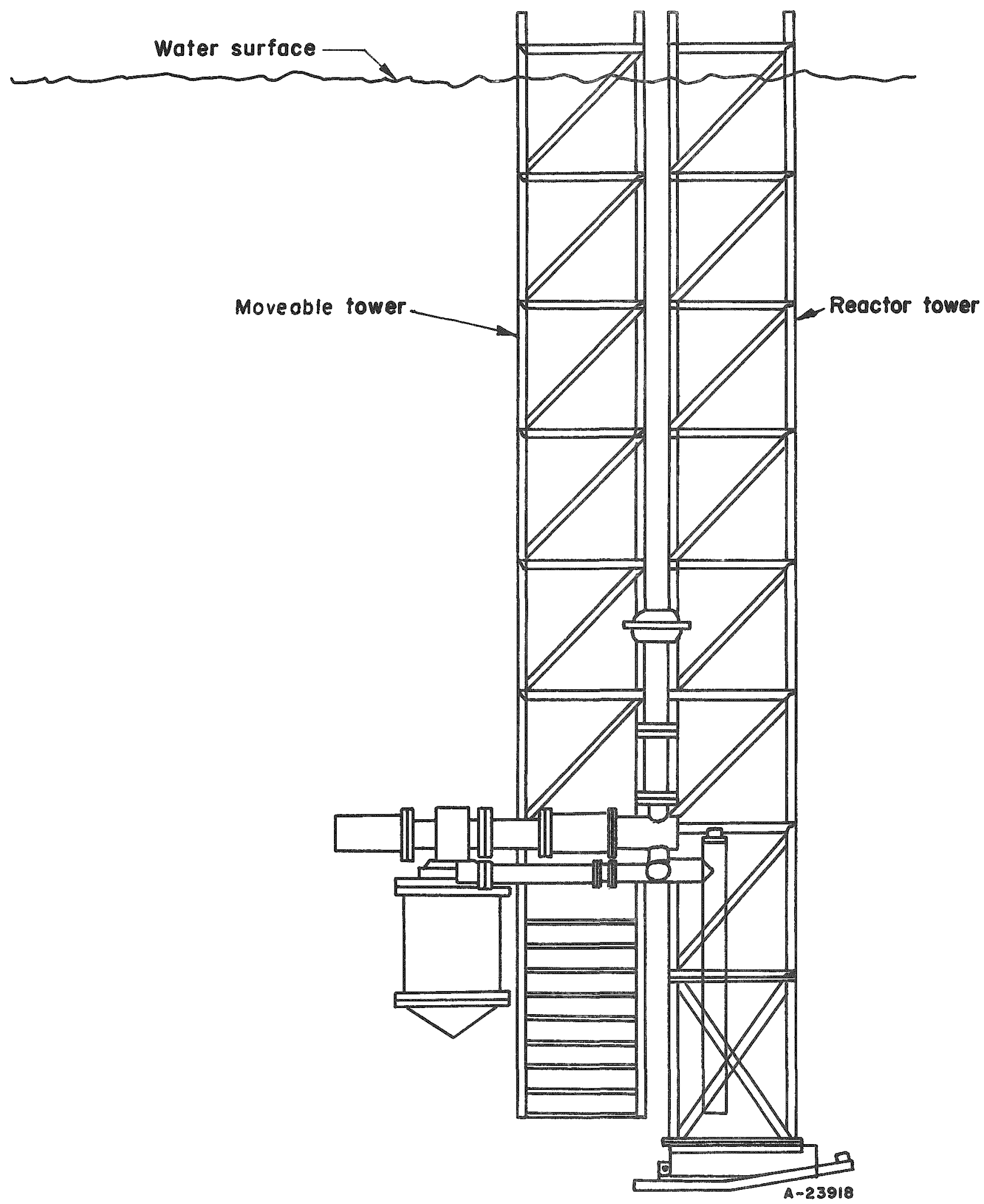

FIGURE 10. SIDE VIEW OF LOOP IN REACTOR POOL 


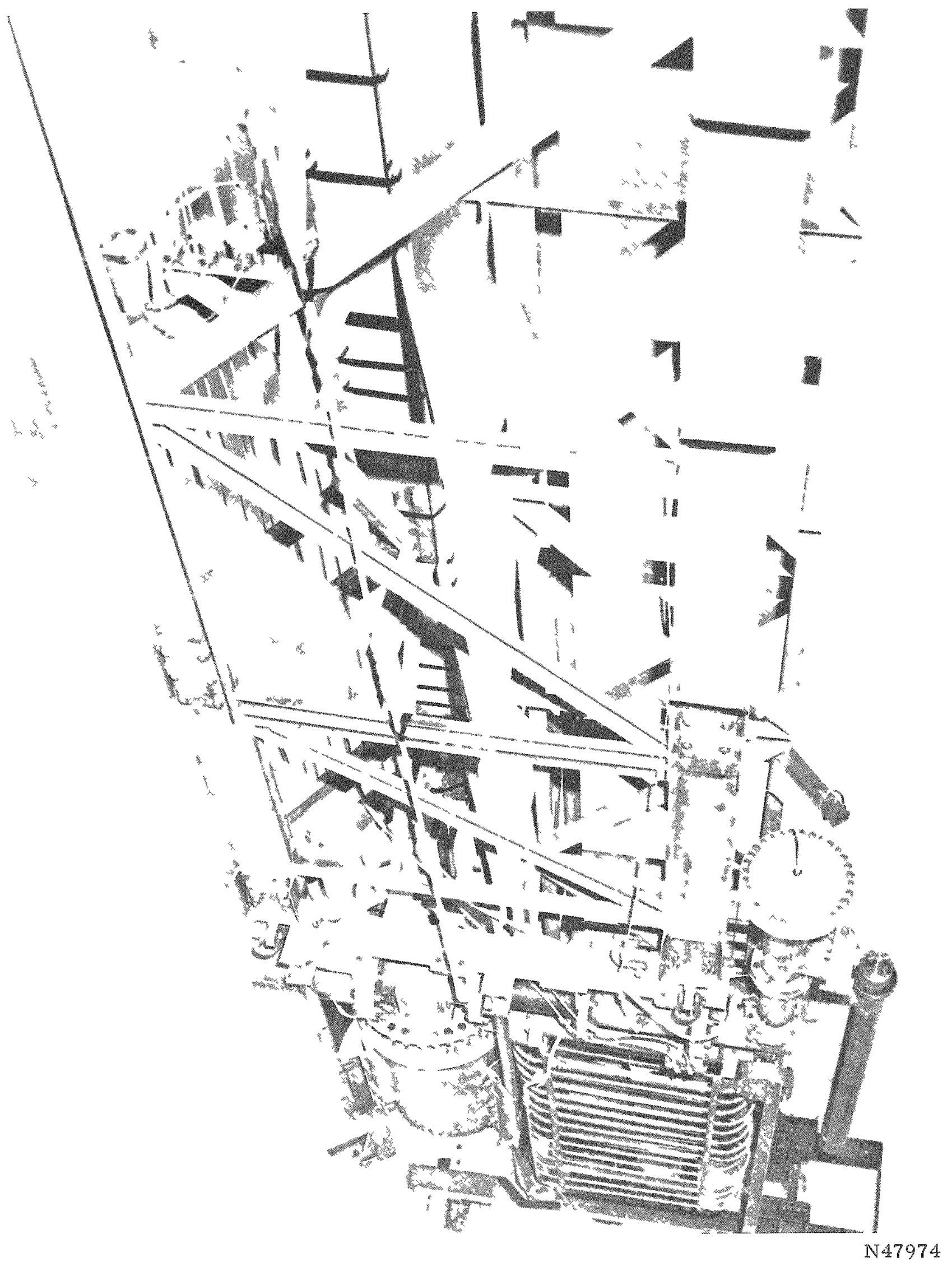

FIGURE 11. SUPPORT TOWER AND LOOP ASSEMBLY 

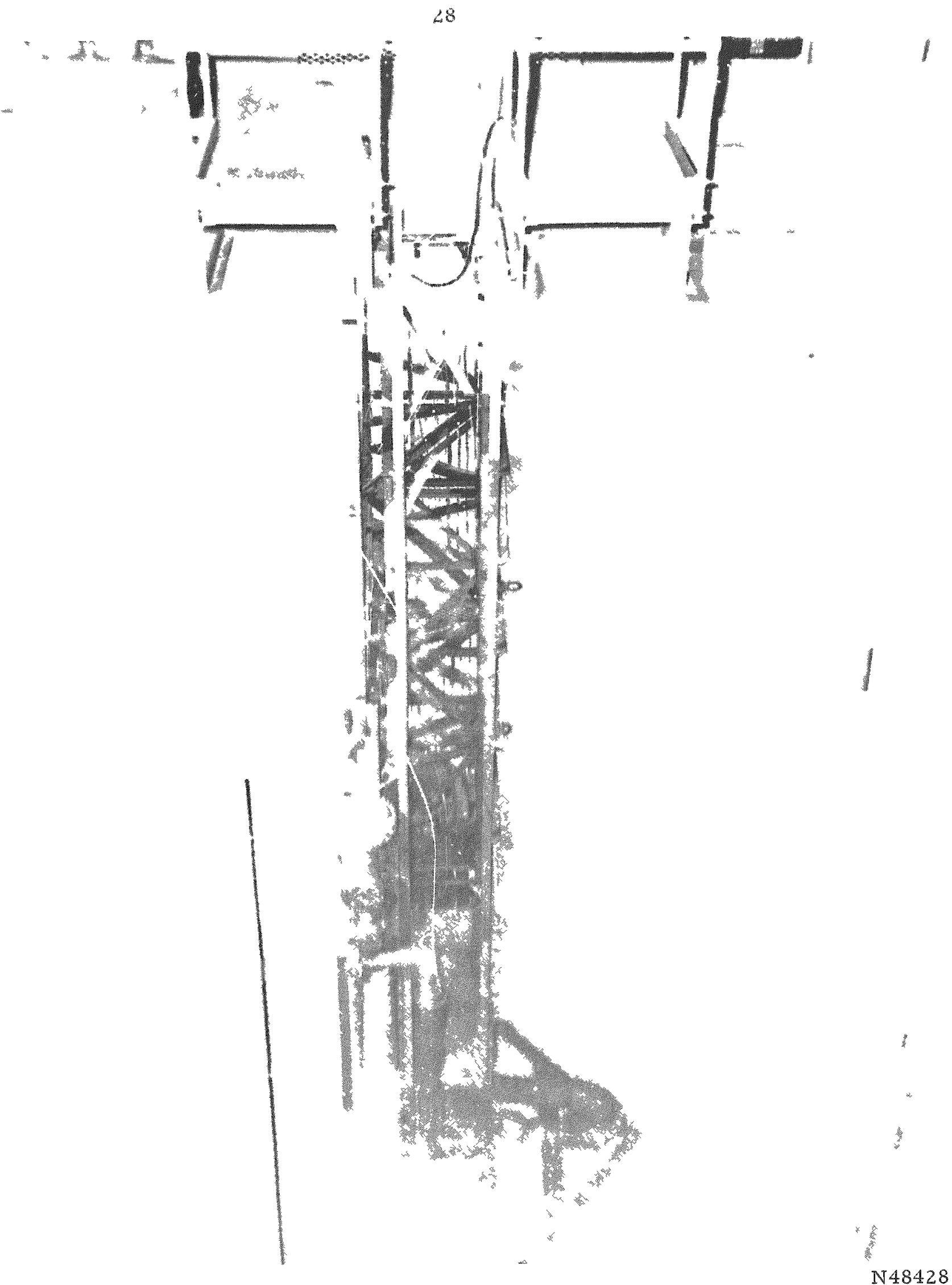

FIGURE 12. LOOP ASSEMBLY, SUPPORT IOWER, AND INSTRUMENT BRIDGE 


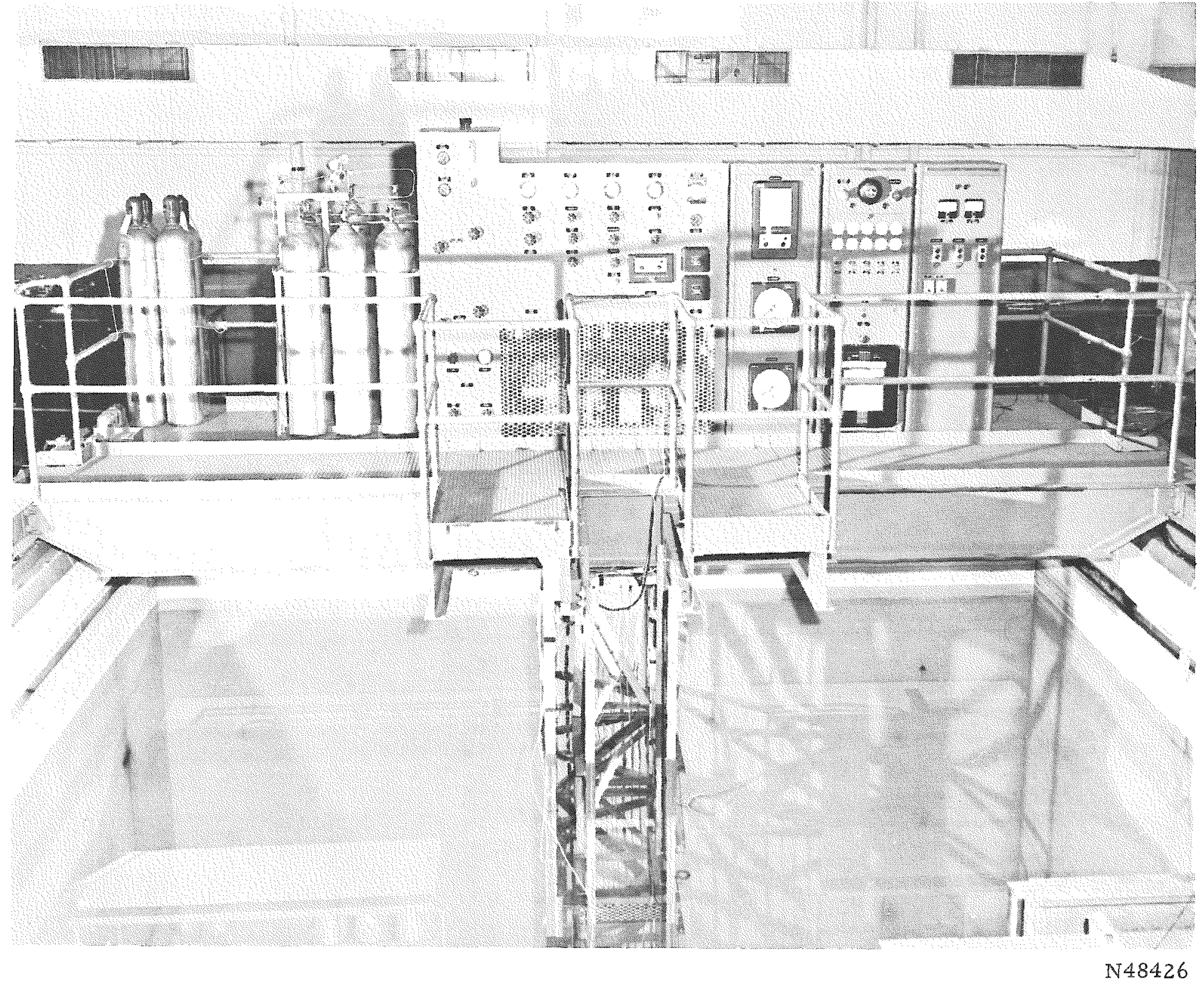

FIGURE 13. INSTRUMENT BRIDGE AND INSTRUMENTATION 
INITIAL IN-PILE OPERATION

The BRR gas-cooled loop has been operating in-pile since March 7, 1958. Since that time it has logged approximately $2200 \mathrm{hr}$ of test operation with two different fuel specimens. The sections following summarize the information concerning the loop performance and operational experience gained thus far.

\section{Performance of the Loop From the Standpoint of}

Gas Flow and Temperature

During the initial phases of the in-pile test on the first fuel-element specimen, approximately 25 sets of data were taken with the loop operating under various conditions of flow rate and specimen power. The flow rate was varied between about 0.05 and $0.3 \mathrm{lb}$ per sec, and the specimen power was varied in the range of 3 to $16 \mathrm{kw}$ (by varying both the reactor power level and the loop position relative to the reactor core). However, in all of the tests the heat-exchanger bypass valve was maintained in the position of minimum heat removal and the system gas pressure was 140 psig.

These data were analyzed to predict the general thermal-performance characteristics of the loop system. The results of this analysis are presented below. It should be recognized that the extrapolation of the correlations derived from these limited data to higher specimen powers and higher gas temperatures contains large uncertainties. These might be expected owing to the heat-loss dependence on gas pressure and the nonlinearity of radiation cooling effects with temperature.

The measured temperatures through the loop system are identified in the schematic diagram of Figure 14.

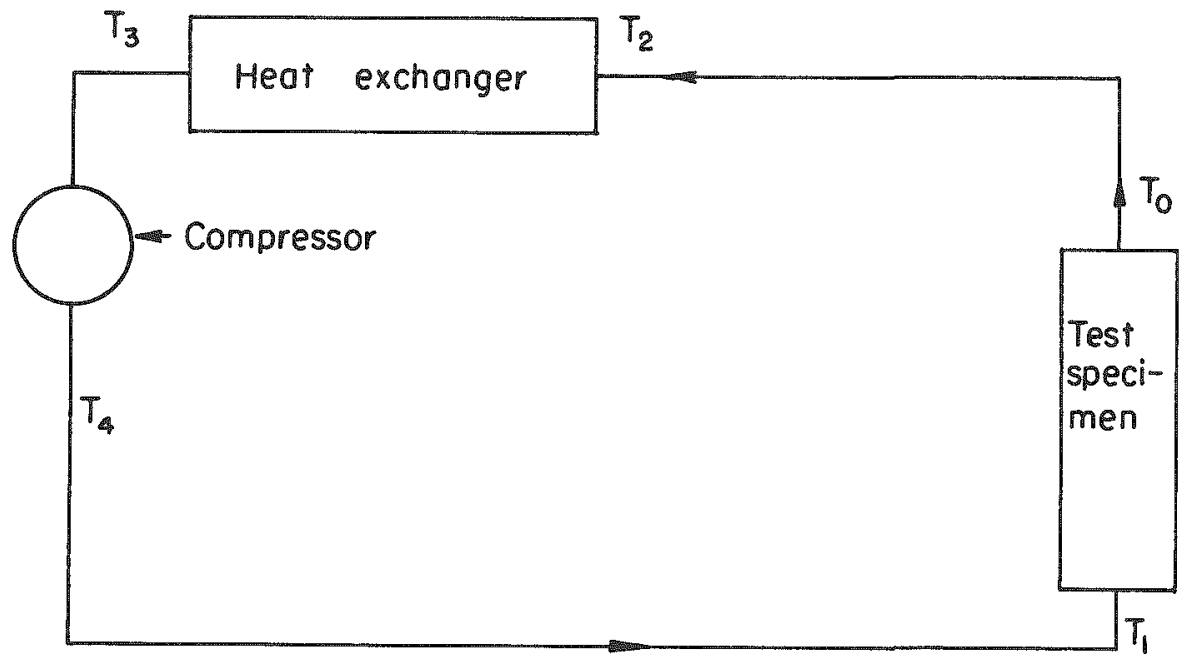

A-29047

FIGURE 14. SCHEMATIC DIAGRAM OF THE LOOP GAS-FLOW SYSTEM 
The salient features of the loop from a thermal-performance standpoint are:

(1) A re-entrant test section where the inlet gas flows down around the outside of the test specimen and up through the specimen

(2) A coaxial piping system which acts as an economizer. The outside pressure walls are aluminum in contact with the reactor pool water; the flowing gas is ducted through Inconel inner pipes. The static gas annulus provides the insulation.

(3) A gas-water shell-and-tube heat exchanger with a partial bypass line

(4) A blower designed to pump the gas at temperatures up to $750 \mathrm{~F}$.

For any specified heat generation in the test specimen, $Q_{0}$, and gas-flow rate, $w$, che equilibrium gas temperatures are determined by the equations given below. The forms of these equations might be readily inferred, to a first approximation, from the usual heat-transfer equations. The constants were determined empirically from a best fit of the in-pile measurements.

A. Coaxial Ducts. Regenerative heat is transferred between inlet and outlet gas in the coaxial ducting sections of the loop. The equation governing this transfer is

$$
T_{0}-T_{2}=0.113 w^{-0.6}\left(T_{0}+T_{2}-T_{4}-T_{1}\right),
$$

where

$$
\begin{aligned}
& T_{0}=\text { specimen-outlet gas temperature, } F \\
& T_{i}=\text { specimen-inlet gas temperature, } F \\
& T_{2}=\text { gas temperature at inlet to heat exchanger, } F \\
& T_{4}=\text { gas temperature at outlet from compressor, } F \\
& \mathrm{w}=\text { gas-flow rate, } \mathrm{b} \text { per sec }
\end{aligned}
$$

B. Heat Exchanger. Heat is exhausted to essentially pool-temperature water at the heat exchanger. The relation between inlet and outlet heatexchanger gas temperature with the bypass valve nominally open (minimum heat-removal condition) is

$$
\left(T_{3}-83\right)=\left(T_{2}-83\right) e^{-0.0935 w^{-0.979}},
$$

where

$$
T_{3}=\text { outlet-gas temperature from heat exchanger, } F \text {. }
$$


C. Compressor. The work done on the gas by the compressor increases the gas temperature through the compressor by the relation

$$
\mathrm{T}_{4}=\mathrm{T}_{3}+40 \text {. }
$$

D. Heat Losses. The heat balance of the system yields a heat loss which has been correlated by the following relationship:

$$
Q_{\ell}=0.0311 \frac{\left(T_{i}+T_{4}-216\right)}{2},
$$

where

$$
Q_{\ell}=\text { heat lost, } \mathrm{kw} \text {. }
$$

These equations may be solved simultaneously to yield the predicted gas-temperature behavior of the system. Figure 15 shows the predicted gas temperature at the specimen outlet as a function of specimen-power generation for various flow rates.

These results indicate that the specimen-outlet gas temperature is strongly dependent upon specimen power at high flow rates. This evidently occurs from two reasons:

(1) A large fraction ( 50 per cent) of the heat generated by the specimen is dissipated in heat losses from the system. These losses increase with increasing $\mathrm{w}$ through the dependence of $\mathrm{T}_{\mathrm{i}}$ and $\mathrm{T}_{4}$ on $\mathrm{w}$.

These losses turned out to be several times higher than predicted by initial calculations of heat flow through static-gas annuli based on conventional natural-convection heat-transfer correlations.

(2) The minimum heat removal by the heat exchanger is strongly dependent upon the flow rate. This result implies that the bypass line through the heat exchanger is not effectively diverting a large enough fraction of the gas flow from the small heat-exchanger tubes.

\section{Procedures for Neutron-Flux Measurements of Loop-Test Specimens}

During an in-pile-1oop testing program it is necessary to make neutron-flux measurements on fuel specimens in situ in the loop. These measurements generally involve foil or wire activation at a low xeactor power level. This procedure requires that flux measurements be made during scheduled reactor shutdown days - a period when time is premium for performing other maintenance functions on the loop system.

In order to provide maximum flexibility in the loop operations, a mock-up loop was constructed for making flux measurements independently of the actual loop system. The mock-up loop is identical to the vertical test section of the actual loop. It is supported from the reactor core bridge and positioned in the normal operating position of the loop test section. 


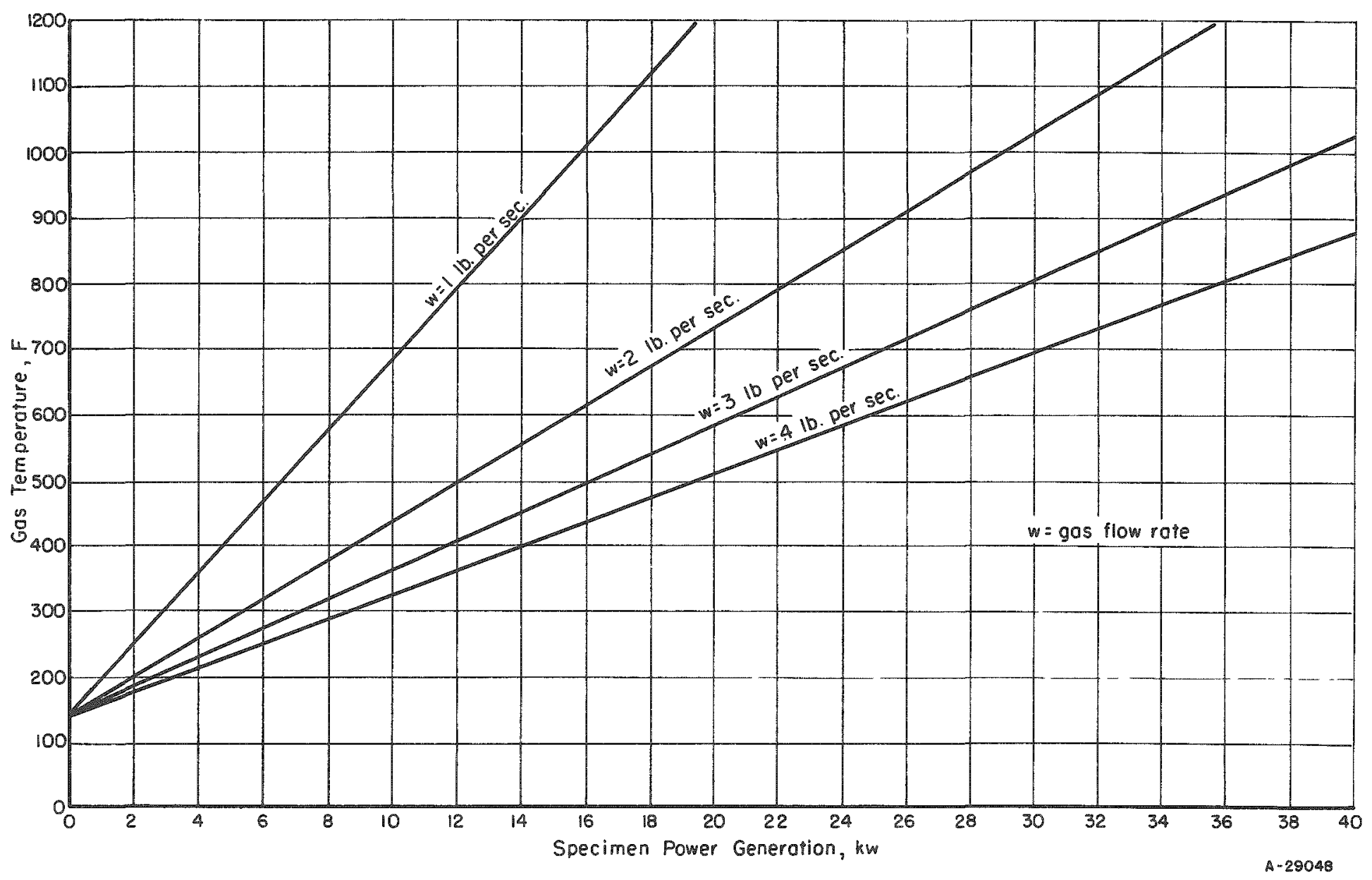

FIGURE 15. GAS TEMPERATURES AT SPECIMEN OUTLET VERSUS SPECIMEN-POWER GENERATION FOR VARIOUS FLOW RATES 
Since the mock-up loop is irradiated only for short times at low reactor power, it does not become highly activated. It can be loaded and unloaded at the reactor pool side with little inconvenience from activation.

This procedure has been exceedingly efficient in permitting parallel operations to be performed during reactor-shutdown periods.

\section{GENERAL DISCUSSION OF THE LOOP DESIGN AND PERFORMANCE}

Thus far the loop and the fuel-assembly specimens under test have been exceedingly well behaved. Loading and unloading, loop startup and shutdown, as well as steadystate operations have gone as well as the loop designers might have hoped. While the loop system has not yet been exposed to a failure of a major component or fuel specimen, the experience thus far indicates that the BRR loop system is a feasible and valuable tool for studying the in-pile behavior of fuel specimens under simulated gas-cooled-reactor conditions.

Through the genexous use of hindsight several factors are apparent which might have been incorporated in the loop design to improve the general performance. These are mentioned here with the hope that they may benefit future designexs of in-pile loops.

(1) Owing to the high heat losses, a gas preheater would greatly increase the inlet-gas temperature obtainable with low-power specimens and high coolant-flow rates.

(2) The heat losses from the system might be reduced by baffles or other insulation in the static-gas regions. However, bulk insulation would have to be selected with the possibility in mind of its exposure to water or oil in the event of loop operational malfunctioning. Also, loose particles of insulation could not be permitted in the flowing gas stream.

(3) A broader range of gas-flow operating conditions might be obtained by pressurizing the cooling water to the heat exchanger. This would permit higher temperature cooling water without boiling heat transfer.

(4) Gas bearings in the blower would considerably simplify the blower system. In the period since this loop design was initiated, gasbearing technology has progressed considerably.

It cannot be overemphasized that the success of the concept of a packaged submerged in-pile-loop system hinges upon the reliability and maintenance-free character of every component in the package. While repairs can and must be planned for, they are bound to be expensive and time consuming relative to a dry, fixed system. This factor forces a conservatism on the designer beyond even the normally stringent safety considerations of in-pile-loop experiments. 